ISSN: 2539-3804 도) (1) @)

\title{
La ironía del profesor de bachillerato: funciones y efectos perlocutivos. Análisis de una muestra representativa ${ }^{1}$
}

\author{
Diego Arias Cortés (1) \\ Juan Pablo Gutiérrez Gómez (1) \\ Miguel Ángel Caro Lopera (1) \\ Universidad del Quindío \\ Armenia, Colombia
}

\section{Resumen}

Este artículo se deriva de un proyecto de investigación que indaga por las funciones y los efectos perlocutivos de la ironía verbal en el aula, a partir del diálogo directo con 104 profesores de Educación Básica Secundaria y Media Vocacional en colegios oficiales del departamento del Quindío. A partir de un diseño metodológico fundamentalmente cualitativo, de corte histórico-hermenéutico, e iluminado por una perspectiva pragmático-socio-discursiva de la ironía verbal, se analizan las principales funciones de la ironía y los efectos perlocutivos de la ironía en el aula de educación básica y media vocacional. Se proyectan algunas implicaciones pedagógico-didácticas sobre la función y los efectos de la ironía en el aula, en diálogo con una definición de ironía como estrategia retórica, socio-discursiva, carnavalizante y pedagógicodidáctica para el diálogo constructivo con las nuevas generaciones.

Palabras clave: efectos perlocutivos; ironía; profesor de bachillerato.

\footnotetext{
${ }^{1}$ Este artículo deviene del proyecto La ironía del profesor y sus efectos perlocutivos. Análisis de una muestra representativa docente en colegios oficiales del Departamento del Quindío, desarrollado por el grupo de investigación en Didáctica de la Lengua Materna y la Literatura (Dilema) de la Universidad del Quindío; código del proyecto: 970 de Vicerrectoría de Investigaciones; fecha de inicio: agosto del 2019; fecha de finalización: febrero de 2021. Duración: 18 meses. Profesores investigadores: Diego Arias Cortés, Juan Pablo Gutiérrez Gómez y Miguel Ángel Caro Lopera. Estudiantes investigadores: Valentina Villa Quintero, Jesica Johana Franco Panqueva, Manuel Alejandro Cristancho Suárez, María Alejandra Echeverry Mejía, Claudia Milena Pinilla Herrera y Yesica Paola Marín Sanabria.
} 


\section{Abstract \\ High school teacher irony: Functions and perlocutionary effects. Analysis of a representative sample}

This article is derived from a research project that inquires into the perlocutionary effects and functions of verbal irony in the classroom. Data consists of direct conversations with 104 teachers of Middle and High Schools in the public sector in Quindío, Colombia. The research design is qualitative, and of historical and hermeneutical nature and grounded on a pragmatic-socio-discursive perspective of verbal irony. Two lines of results are discussed: 1 ) the main functions of irony; 2) the perlocutionary effects of irony in the classroom of secondary education. After this analyses, pedagogic and methodological implications of the function and effects irony has in the classroom are discussed. Conclusions include a definition of irony as a rhetorical, socio-discursive, carnivalizing, pedagogical and didactic strategy for constructive dialogue with the new generations.

Key words: perlocutionary effect; irony; high school teacher.

\section{Résumé}

L'ironie du professeur de collège et lycée : fonctions et effets perlocutoires. Analyse d'un échantillon représentatif

Cet article est issu d'un projet de recherche qui étudie les fonctions et les effets perlocutoires de l'ironie verbale en cours, basé sur un dialogue direct avec 104 enseignants de collèges et lycées publics du département du Quindío. Á partir d'une méthodologie qualitative, de nature historico-herméneutique, et la lumière de la perspective pragmatique-socio-discursive de l'ironie verbale, l'on cherche à analyser les fonctions principales de l'ironie et les effets perlocutoires de l'ironie dans la salle de classe de l'enseignement secondaire. En conclusion, certaines implications pédagogiques et didactiques sont projetées sur la fonction et les effets de l'ironie en cours, en dialogue avec une définition de l'ironie en tant que stratégie rhétorique, socio-discursive, carnavalisante et pédago-didactique, en faveur d'un échange constructif avec les nouvelles générations.

Mots-clés: professeur de lycée; enseignement et formation; ironie; langue maternelle. 


\section{SOBRE LOS AUTORES}

\section{Diego Arias Cortés}

Docente de contrato, categoría asociado. Magíster en Estudios Hispánicos de la Universidad de Cádiz, España. Profesor de la Licenciatura en Literatura y Lengua Castellana (Universidad del Quindío). Áreas de docencia e investigación: psicolingüística (desarrollo del lenguaje) y sociolingüística (discurso oral).

Correo electrónico: dariasc@uniquindio.edu.co

\section{Juan Pablo Gutiérrez Gómez}

Docente catedrático, categoría asistente. Magíster en lingüística (Universidad Tecnológica de Pereira). Profesor del programa de Licenciatura en Literatura y Lengua Castellana (Universidad del Quindío). Áreas de docencia e investigación: Lingüística, análisis del discurso, sintaxis de la lengua castellana.

Correo electrónico: jupagutierrez@uniquindio.edu.co

\section{Miguel Ángel Caro Lopera}

Docente de planta, categoría asociado. Doctor en Ciencias de la Educación (Universidad del Quindío, RUDECOLOMBIA). Profesor del programa de Licenciatura en Literatura y Lengua Castellana y de la Maestría y el Doctorado en Ciencias de la Educación (Universidad del Quindío). Áreas de docencia e investigación: lingüística, didáctica de la lengua materna, ciencias de la educación, argumentación, retórica e ironía verbal.

Correo electrónico: macaro@uniquindio.edu.co

\section{Cómo CITAR ESTE ARTÍcUlO}

Arias, D., Gutiérrez, J., Caro, M. (2021). La ironía del profesor de bachillerato: funciones y efectos perlocutivos. Análisis de una muestra representativa. Lenguaje, 49(2), 338-364. https://doi.org/10.25100/lenguaje.v49i2.11003. 


\section{INTRODUCCIÓN}

Si investigar sobre la ironía verbal supone, de suyo, penetrar en un territorio pródigo en retos y hallazgos, mucho más lo sería si pusiéramos su comprensión en clave del discurso del profesor como uno de los nodos del sistema didáctico. Reconocemos que los estudios sobre la ironía han alcanzado su mayoría de edad, gracias a trabajos como los de Alba (2002), Attardo (2000), Kalbermatten (2006), Sperber y Wilson (1981) y YusRamos (2009), entre tantos otros; pero también advertimos que la ironía en el aula aún esconde mucho por investigar, pues son pocos los trabajos que se han ocupado del asunto para el caso colombiano, como los de Arrieta (2013), Caro et al. (2020) y TorresHernández (2012). En este último se propone la idea de una ironía como lubricante didáctico para estimular ambientes de aprendizaje más dialógicos, dinámicos y creativos. Sin embargo, si tenemos en cuenta que "la forma de decir del docente universitario es para los alumnos tan importante como lo que dice" (TorresHernández, 2012, p. 470), hemos de reconocer que la ironía introduce distintos niveles de tensión de aula, a través de sus tipologías más comunes: desde la antífrasis del decir lo contrario de lo que se piensa, hasta el sarcasmo que muerde la carne, sin dejar de lado los posibles insultos que se salen del cauce comunicativo ${ }^{2}$. En este marco de consideraciones conviene anotar que nos adscribimos teóricamente a la concepción de la ironía que discutimos en el trabajo de Caro et al. (2020) como dispositivo de diversos tipos: retórico, pues consigue la adhesión del auditorio en virtud de su polifonía y 341 poder suasorio (Arrieta, 2013; Ruiz, 2012; Sopeña, 1997; Yus-Ramos, 2009); sociodiscursivo, pues vehicula funciones de "evaluación, ataque verbal y diversión" (Alba, 2002, p. 558); carnavalizante, pues subvierte las formas y estructuras de los textos (Bajtín, 1976; Ducrot, 1988); y pedagógico, pues se erige como "una nueva forma comunicativa en las aulas de clase y la más pertinente para la época" (TorresHernández, 2012, p. 471).

Desde estos intereses, la investigación de la cual se deriva este artículo discurre por las aulas de la Educación Básica Secundaria y Media Vocacional en los colegios oficiales del Departamento del Quindío, a partir de la hipótesis de trabajo sobre los tipos de ironía que usa el profesor, los procedimientos retóricos que la caracterizan, las intenciones que revela, los logros que consigue, los criterios de los que se vale, las variables contextuales que tiene en cuenta y las respuestas que detona en los estudiantes. Tales propósitos se sintetizan en la pregunta de investigación: ¿Qué

\footnotetext{
${ }^{2}$ Teóricamente posicionamos el sarcasmo, en su etimología de morder la carne, como un paso más allá de la ironía, en términos de que ya no hay discrepancia entre lo dicho y lo pensado. Aunque con Beristáin (1995) reconocemos el sarcamo como "escarnio, ironía cruel, brutal, insultante y abusiva" (p. 275), nos adherimos a Huang et al. (2015) en torno a la tesis que encabeza el título de su trabajo: "The highest form of intelligence: Sarcasm increases creativity for both expressers and recipients".
} 
funciones cumple la ironía en el aula de clase de bachillerato de colegios públicos en el departamento del Quindío y qué efectos perlocutivos provoca en los estudiantes ${ }^{3}$ ?

Para el caso concreto de este artículo nos centraremos en el análisis de algunas funciones y efectos. Ya el análisis de tales frentes de resultados redunda en diversos puntos de discusión que queremos materializar en escenarios estratégicos acerca de la actitud de tacto y prudencia que, antes de jugar a la ironía, debería el profesor tener en cuenta (Caro, 2020; Caro et al., 2020). Al fin y al cabo, ironizar, aunque resulte excitante, no está exento de peligros; ya lo decía Jankélévitch (2012), en su estilo metafórico característico: "el peligro está en una jaula: la ironía va a verlo, lo imita, lo provoca, lo ridiculiza, lo mantiene para su recreación; incluso se arriesgará a través de los barrotes para hacer la diversión tan peligrosa como sea posible"; concluye el autor que "la maniobra puede descarriarse, y por eso murió Sócrates" (p. 12).

\section{Metodología}

El proyecto La ironía del profesor y sus efectos perlocutivos. Análisis de una muestra representativa docente en colegios oficiales del Departamento del Quindío sigue un diseño metodológico fundamentalmente cualitativo de corte histórico-hermenéutico, basado en un corpus de 104 entrevistas semiestructuradas a profesores de Educación Básica Secundaria y Media Vocacional en colegios oficiales del Quindío. La población resultante fue de un $35 \%$ de mujeres y $65 \%$ de hombres; con franjas de edades entre los 20 y 35 años (43\%), 36 y 50 (54\%) y más de 50 (3\%). La entrevista cubrió todos los municipios adscritos a la Secretaría de Educación Departamental en un rango de 72 \% de instituciones ubicadas en el sector urbano y un $28 \%$ en el rural. Una vez calculado el número de 104 como muestra representativa del $10 \%$ del total de profesores oficiales que laboran en dichos niveles educativos, el equipo investigador procedió a la entrevista solo a quienes concedieran autorización, mediante consentimiento informado, hasta completar el corpus requerido. Cabe anotar que para facilitar la pluralidad de opiniones no se presentó ninguna restricción en cuanto a nivel de formación o área de desempeño. Optamos por el instrumento la entrevista semiestructurada, en virtud de que "el entrevistador tiene la libertad de introducir preguntas adicionales para precisar conceptos $u$ obtener mayor información sobre los temas deseados" (Hernández et al., 2006, p. 597). En este caso, las preguntas predeterminadas indagaban, en primer lugar, por la experiencia del profesor como estudiante (si recordaba a algún profesor irónico que le hubiera marcado la vida y, en

\footnotetext{
${ }^{3}$ En cuanto al análisis de los efectos perlocutivos provocados en los estudiantes, el equipo investigador del proyecto se vio en la necesidad de circunscribirse a los datos que podía conseguir de los docentes entrevistados y apelar, por ejemplo, a sus propias vivencias de sus épocas de estudio y a la lectura que hacían de las reacciones de sus estudiantes cuando les dirigían ironías. Ante la conclusión de que tal medida no es suficiente para calcular la magnitud del fenómeno, el grupo investigador construye un nuevo proyecto en el que se espera abordar exclusivamente el asunto; se trata de la investigación, aún en fase de evaluación, La ironía verbal en el aula de clase y su recepción en el estudiante (Universidad del Quindío).
} 
caso afirmativo, si tenía presente alguna ironía que le hubiera referido y qué efectos positivos o negativos le suscitaron tales ironías ${ }^{4}$ ). En segundo lugar, se le preguntaba si, en su experiencia como profesor, recurría a la ironía en las interacciones con sus estudiantes (en caso positivo, se le solicitaba ejemplos de ironías para situaciones disruptivas de clase, como llegadas tarde, indisciplina, incumplimiento con las tareas o respuestas equivocadas a conceptos que los estudiantes debían dominar). En tercer lugar, se buscaba su opinión en torno a si advertía efectos positivos o negativos en sus ironías, además si reconocía algunos puntos de quiebre para refrenar sus deseos de hacerlo. Se cerraba el libreto predefinido con la pregunta por el valor pedagógico o didáctico que los profesores encontraran en sus ironías.

En términos generales, el proyecto supuso el desarrollo de 5 fases estrechamente ligadas a objetivos específicos de orden metodológico ${ }^{5}: 1$ ) preparación del grupo investigador en cuanto a la revisión del estado del arte y de las bases teóricas sobre el concepto de ironía verbal; 2) la definición de la muestra representativa, el contacto con los profesores elegidos, la firma de los consentimientos informados y la validación del instrumento base para las entrevistas semiestructuradas; 3) el levantamiento de las entrevistas semiestructuradas; 4) el análisis del corpus a través de una rúbrica sobre las preguntas formuladas y sesiones de análisis grupal de las grabaciones conseguidas y de las experiencias de los entrevistadores; 5) la socialización de los resultados con los profesores entrevistados y con la comunidad académica.

343 Más allá del diseño operativo, importaban los principios para investigación de esta naturaleza, en virtud de la elección histórico-hermenéutica asumida. Al respecto, resaltamos: 1) La concepción de hermenéutica como actitud transversal del proyecto que se expresa "en la elección del enfoque y de la metodología, en el tipo de preguntas que se formulan para recoger los datos, en la recolección de los datos y, por último, en el análisis de dichos datos" (Martínez, 2004, p. 101). 2) El valor de esa actitud hermenéutica para analizar lo que ocurre en el aula, pues, según el mismo Martínez (2004), "no solo los textos escritos, sino toda expresión de la vida humana es objeto de la interpretación hermenéutica" (p. 104); de ahí la importancia de las sesiones con el grupo investigador para comprender lo que decían los profesores en las entrevistas semiestructuradas, a la luz de las condiciones propias de su contexto. 3) La imposibilidad de una interpretación aséptica, objetiva, transparente, de los textos; en

\footnotetext{
${ }^{4}$ Las respuestas recogidas en este ítem llevaron a que el equipo investigador reconociera la necesidad de un nuevo proyecto que se centrara en las reacciones directas de los estudiantes a la ironía del profesor; justamente este proyecto, como se indicó antes, se halla en fase de evaluación bajo el nombre de La ironía verbal en el aula de clase y su recepción en el estudiante (Universidad del Quindío) y busca redondear el análisis que la presente investigación ofrece.

${ }^{5}$ Estas fases, en el proyecto citado, respondieron al objetivo general de analizar el lugar, las funciones y los efectos perlocutivos de la ironía verbal en el aula de clase, a partir de una muestra representativa de entrevistas semiestructuradas a profesores de Educación Básica Secundaria y Media Vocacional en colegios oficiales del departamento del Quindío, con el fin de reflexionar sobre el papel de la ironía en las interacciones de aula como dispositivo pedagógico y didáctico.
} 
esto nos apoyamos en Gurdián-Fernández (2007), que nos recuerda que inevitablemente "cualquier conocimiento de las cosas viene mediado por una serie de prejuicios, expectativas y supuestos recibidos de la tradición que determinan, orientan y limitan nuestra comprensión" (p. 146). De los resultados conseguidos, socializamos en este artículo dos grandes categorías que, a continuación, exponemos.

\section{Resultados}

Presentamos de modo sucinto dos frentes de resultados: en primer lugar, un análisis del comportamiento de la muestra analizada en el marco de las principales funciones de la ironía, según Alba (2002); en segundo lugar, una mirada a los efectos perlocutivos de la ironía que se alcanzan a dilucidar tras las entrevistas semiestructuradas, en paralelo con los aportes formulados por Torres-Hernández (2012).

\section{Las funciones de la ironía del profesor de bachillerato}

En este apartado presentamos un análisis de varias muestras de ironías usadas por los profesores en las aulas de clase. Para ello se sigue la propuesta de Alba (2002), quien aborda este fenómeno desde tres funciones principales: la evaluación, el ataque verbal y la diversión. Las ironías emergen en cuatro situaciones de aula que responden, según la entrevista aplicada en campo, a la pregunta: ¿en su experiencia como profesor, recurre a la ironía en las interacciones con sus estudiantes? Para dar cuenta de este objetivo titulamos cada situación, luego presentamos porcentajes de ironías realizadas por los profesores, ejemplos y análisis de estos; terminamos con una breve conclusión.

\section{Situación 1. Cuando un estudiante llega tarde a clase}

En esta situación de aula, el $63.46 \%$ de los entrevistados declararon ironizar cuando un estudiante llega tarde a clase. Algunos profesores manifestaron que lo hacían con el fin de causar en ellos un escarmiento que los lleve a la reflexión y cambiar la manía. Veamos, entonces, algunos ejemplos y su análisis.

Las dos primeras muestras de ironías que figuran en la Tabla 1 son prototípicas de esta situación de aula; por su valor circunstancial - en tanto enunciados antifrásticos - como lo podemos observar, varios profesores las utilizan. Ambas pretenden generar un cambio en el oyente a la vez que constituyen un tipo de reproche, precisamente por dicho comportamiento inapropiado. En otras palabras, estas muestras de lenguaje irónico tienen algo de ataque verbal, pues, como señala Alba (2002): "When attacking a certain victim, speakers want, at the same time, to distance themselves from these victims or from certain behaviour patterns" (p. 480). La intención que se muestra es, ante todo, intentar modificar el comportamiento del otro al tiempo que se toma distancia de este. Según la autora, el ataque verbal es una de las funciones generales de la ironía que puede ocurrir en simultáneo con otras, por 
ejemplo, el reproche (Alba, 2002). Y así como hay algo de ataque verbal y de reproche, la evaluación y la diversión también tienen su lugar en las ironías empleadas en esta circunstancia, pues esta es una de esas situaciones en las que la coocurrencia de las funciones de la ironía parece diluir cualquier límite. En los demás ejemplos de la tabla se advierte algo similar; sin embargo, queremos destacar el valor del dicho popular en P017, pues la circunstancia de la llegada tarde del estudiante da vida a que proverbios y aforismos se constituyan, no solo en amonestaciones, sino también en ironías antifrásticas que denuncian justamente lo que el estudiante debió hacer y no hizo: madrugar; en este caso los resultados dialogan con las funciones irónicas del proverbio que propone Gómez-Jordana (2007).

Tabla 1. Ironías usadas por los profesores cuando un estudiante llega tarde a clase

\begin{tabular}{|c|c|}
\hline Código del profesor & Ejemplos de ironías \\
\hline $\begin{array}{lll}\text { P037, P042, } & \text { P051, } \\
\text { P052, P059, } & \text { P062, } \\
\text { P066, } & \text { P071 } & \end{array}$ & Se le pegaron las cobijas \\
\hline $\begin{array}{lll}\text { P020, } & \text { P024, } & \text { P030, } \\
\text { P035, P050, } & \text { P074, } \\
\text { P081, P082, } & \text { P085, } \\
\text { P086, } & \text { P087, P097 }\end{array}$ & Buenas noches (en la mañana) \\
\hline P002 & El más puntual de la clase, por favor, siga \\
\hline P004 & Madrugó (cuando evidentemente no lo hizo) \\
\hline P006 & Cuando necesite la muerte ya sé a quién voy a mandar por ella \\
\hline P0016 & Uy, ese milagro, tenemos un estudiante nuevo \\
\hline P017 & Al que madruga, Dios le ayuda \\
\hline P022 & $\begin{array}{l}\text { Muy buenas noches, me imagino que estaba estudiando o haciendo la } \\
\text { tarea que estaba pendiente }\end{array}$ \\
\hline P030 & -Qué alegría verlo, hoy llegó cinco minutos más temprano que ayer \\
\hline P043 & $\begin{array}{l}\text { - Eh, ¡qué milagro! Llegó temprano } \\
\text { — ¡Bravo! Bien pueda, fue el primero }\end{array}$ \\
\hline P056 & Querido, tú como siempre tan responsable \\
\hline
\end{tabular}

En términos generales se observa cómo los profesores hacen uso de la ironía con tintes humorísticos para reprochar una acción específica en sus estudiantes. Para ello se apela a diferentes estrategias. En algunos casos, los profesores recurren a 
expresiones populares que se utilizan en situaciones semejantes, por ejemplo: Madrugó; Al que madruga, Dios le ayuda. Estas formas del lenguaje, recurrentes en la cotidianidad, contribuyen a despojar a la ironía de ciertas connotaciones negativas y la embarcan por las cálidas aguas de la risa y el humor. Por tal motivo algunos educadores afirman que los efectos que consiguen con sus ironías son, en su mayoría, positivos, debido a que la diversión que las envuelve propicia un entorno más tranquilo y estimulante para sus estudiantes. En esta línea argumentativa caen muy bien las palabras de Torres-Hernández (2012):

Ante el uso de este tipo de ironías por parte del docente, los estudiantes perciben que la comunicación es más fluida ya que permite el diálogo abierto, donde además caben el chiste y otros actos que dinamizan la clase. En aquellas ironías con contenido positivo no hay censura ni reproche que aniquile, sino críticas constructivas, características propias de la ironía abierta. (p. 468).

En los demás ejemplos, los profesores recurren a otra estrategia para intentar modificar los hábitos de sus estudiantes. Usan un aparente halago para evaluar su comportamiento, como se observa en: El más puntual de la clase...; Cuando necesite la muerte ya sé a quién voy a mandar por ella; Muy buenas noches, me imagino que estaba estudiando o haciendo la tarea que estaba pendiente; Qué alegría verlo, hoy llegó cinco minutos más temprano que ayer; Eh, iqué milagro! Llegó temprano; Querido, tú como siempre tan responsable. Estas ironías destacan cualidades que sus "víctimas" no poseen: no son los más puntuales, quizá no son los más estudiosos ni los más responsables. La adjudicación pública de aparentes virtudes, aparte de censurar un comportamiento, resulta jocosa dados los antecedentes de los chicos implicados. Es como atribuir belleza a aquello que no lo tiene y que, en el proceso, nos resulta caricaturesco.

En suma, esta situación de aula, con sus respectivas ironías, demuestra lo maleables que son los contornos del hecho irónico, ya que, como se observa en el análisis previo, sus funciones se disuelven según las miradas, los sujetos implicados, las intenciones, los juegos de poder, entre otros factores.

\section{Situación 2. Uso de la ironía cuando el estudiante no hace las tareas}

En este contexto el $48.07 \%$ de los profesores acude a la ironía. Quienes no lo hacen señalan que en tal situación prefieren ser más letales y poner mala nota, sin piedad, o simplemente ser directos con los estudiantes desde el principio. Los ejemplos y su análisis se exponen enseguida en la Tabla 2: 
Tabla 2. Ironías usadas por los profesores cuando el estudiante no hace las tareas

\begin{tabular}{|l|l|}
\hline $\begin{array}{c}\text { Código del } \\
\text { profesor }\end{array}$ & \multicolumn{1}{c|}{ Ejemplos de ironías } \\
\hline P063 & $\begin{array}{l}\text { Pobrecito, yo me imagino que estaba muy cansado de trabajar para mantener } \\
\text { la familia y por eso no hizo la tarea, no se preocupe }\end{array}$ \\
\hline P032 & Imagino que se encontró al ladrón de cuadernos en el camino \\
\hline
\end{tabular}

En estas muestras prevalece el recurso humorístico para interpelar al estudiante. Con ellas se intenta modificar cierto comportamiento sin necesidad de atacar o ser directo con el destinatario. Esta forma del lenguaje también atenúa el acto de habla directivo (Searle, 1969/1980) implicado. Da la impresión de que el profesor se pone de parte del estudiante en unas situaciones absurdas que él mismo plantea. Expresiones como Pobrecito, yo me imagino e imagino dan cuenta de ese intento por parte del profesor de estar del lado de la persona implicada, todo, por supuesto, en una especie de ficción cuya función parece ser evaluar al otro y buscar que cambie su comportamiento. Así pues, la función de evaluación también se manifiesta acá. A esto se suma una de las funciones específicas que Alba (2002) denomina como rapport building; esto es, "Creation of solidarity among the participants of discourse" (p. 479). Aunque, como se observa en los casos referidos, es simplemente una ilusión de 347 solidaridad entre ambas partes. Consideramos, entonces, que los ejemplos están cargados de humor por las situaciones que plantean y constituyen formas de evaluar el comportamiento de los estudiantes ante tal situación.

Situación 3. Profesores que utilizan la ironía cuando un estudiante habla permanentemente en clase

En cuanto al porcentaje de uso de la ironía, el $47.11 \%$ de los profesores la utiliza en esta situación de aula. Quienes la usan manifiestan que "usamos la ironía con el fin de que los estudiantes tomen conciencia de que deben prestar atención y hacer silencio". Los demás profesores recurren a un lenguaje asertivo, tal como se documenta en la Tabla 3.

Tabla 3. Ironías usadas por los profesores cuando un estudiante habla permanentemente en clase

\begin{tabular}{|l|l|}
\hline $\begin{array}{c}\text { Código del } \\
\text { profesor }\end{array}$ & \multicolumn{1}{c|}{ Ejemplos de ironías } \\
\hline P032 & Habla más que loro mojado \\
\hline P002 & Esperemos que termine de hablar el más callado del salón \\
\hline P069 & $\begin{array}{l}\text { Ya que está hablando tanto, me imagino que sabe mucho, pues venga y nos } \\
\text { da la clase }\end{array}$ \\
\hline
\end{tabular}


El último ejemplo de la Tabla 3 es una muestra de ironía negativa. Según Alba (2002): “(...) used when the intention of the speaker is to criticize or express some kind of negative attitude or feeling towards himself, the hearer, a third party or a situation" (p. 386). Es evidente que el profesor expresa una actitud negativa al destinatario debido a su comportamiento en esa circunstancia. Para tal fin ataca su imagen, pues le da a entender todo lo contrario de lo que afirma (me imagino que sabe mucho); es decir, que es una persona que sabe poco. En este sentido parece que se recurre a la ironía en una de sus definiciones primarias ${ }^{6}$, con el propósito de atacar al otro y conducirlo a que cambie su proceder. Al tiempo que hay un ataque verbal se vislumbran tonos de reproche, queja y manifestación de poder por parte del profesor. En este último caso, otra posible interpretación de me imagino que sabe mucho sería que no sabe nada, en comparación con el profesor usuario de tal ironía. Nos aventuramos a tal interpretación siguiendo algunas líneas de Alba (2002) en las que precisa que una de las funciones específicas de la ironía es la manifestación de poder. Esta se da cuando "(...) there may be occasions on which a person uses irony to show his/her interlocutor/s that s/he is a person that holds some kind of power" (p. 510). Quizá en una situación como esta sea la demostración de tal poder lo adecuado para determinar el cambio de comportamiento en el interlocutor, más que el ataque verbal mismo.

En cuanto a su forma, los otros ejemplos son una ironía antifrástica (el tercero) y una hipérbole (el primero). Al igual que el ejemplo analizado en el párrafo anterior, con estas ironías se intenta cambiar el comportamiento del destinatario. Las dos primeras son usos lingüísticos prototípicos en situaciones semejantes fuera del aula, o sea, es común que las apliquemos en otros ámbitos; casi que se han fijado en nuestro repertorio de frases para situaciones en las que deseamos que alguien no hable demasiado. Así pues, a riesgo de exagerar en la interpretación, ambos ejemplos semejan ecos propios de escenarios de la cotidianidad que se reproducen en el aula. Los consideramos como ecos en dos sentidos. Por un lado, su forma lingüística se repite multitud de veces casi sin cambios en su estructura sintáctica y por lo general acompañada de un tono humorístico; por otro, esa forma de habla impele a un fin común: que el destinatario finalice su discurso o, al menos, no participe tanto de la interacción comunicativa. En este sentido no nos alineamos con la mención ecoica que establecieron Sperber y Wilson (1981), puesto que las expresiones irónicas señaladas no implican resaltar su irrelevancia en las circunstancias en las que emergen, más bien se direccionan al cambio de hábito en quien escucha.

\footnotetext{
${ }^{6}$ En sus acepciones clásicas, la ironía se entiende como "una figura del lenguaje por la que se quiere hacer entender lo contrario de lo que se dice" (Alonso-Quecuty, 1993, p. 114).
} 
Situación 4. Cuando un estudiante responde equivocadamente a una pregunta muy obvia

En esta ocasión el $77.88 \%$ de los profesores prefiere no ironizar y el $22.11 \%$ restante sí lo hace. La mayor parte de los profesores manifiesta que prefiere no ironizar, porque teme que los estudiantes se sientan mal; además, señalan que es normal que sean los mismos compañeros (los demás estudiantes) quienes ironicen y "hagan bulla" cuando la respuesta es equivocada. Algunos ejemplos de este fenómeno se documentan en la Tabla 4.

Tabla 4. Ironías usadas por los profesores cuando un estudiante responde equivocadamente a una pregunta muy obvia

\begin{tabular}{|l|l|}
\hline \multicolumn{1}{|c|}{$\begin{array}{c}\text { Código del } \\
\text { profesor }\end{array}$} & \multicolumn{1}{c|}{ Ejemplos de ironías } \\
\hline P063 & Ay, amor, se le derramó la materia gris \\
\hline P041 & $\begin{array}{l}\text { No, mijo, pero cacumen, piense, mueva esa cabecita a ver si esas neuronas le } \\
\text { funcionan }\end{array}$ \\
\hline P048 & Usted se las sabe todas, se las pilla todas \\
\hline
\end{tabular}

Siguiendo la propuesta de Alba (2002), podemos observar en los tres ejemplos de la Tabla 4 muestras irónicas cargadas de humor que se dirigen a burlarse del interlocutor. Es lo que la autora ha etiquetado, dentro de las funciones específicas de la ironía, como Teasin/poking fun at one's interlocutor (p. 512). Las consecuencias de esta estrategia lingüística o los efectos perlocutivos (Searle, 1969/1980) que de ella se desprenden son impredecibles, pues suponemos que unas veces se reacciona de buena manera (quizá el estudiante propone otra respuesta) y otras, como indicaron los profesores, el estudiante se siente mal porque ha quedado en ridículo frente a sus compañeros. Dada la intención manifiesta en estos ejemplos, los podemos interpretar también como formas de ataque verbal.

Si nos detenemos un poco más en estos enunciados, sobresale una característica común: las formas de tratamiento. P063 y P041 recurren a formas de tratamiento nominal (Placencia et al., 2015), verbigracia, "amor" y "mijo". Ambas expresan un tratamiento fraternal, aparentemente cariñoso. Estas palabras se suelen utilizar entre personas con algún tipo de vínculo afectivo (amistoso-familiar o amoroso) y develan confianza y consideración entre ellos. Quizá, ante el temor de que el otro se sienta mal, se seleccionan estos recursos nominales con el ánimo de atenuar, aunque sea un poco, el efecto negativo de estas burlas. Si nos ubicamos en una perspectiva diferente, entonces irrumpe un destello del rapport building que discutimos líneas arriba, pues algo de solidaridad trasmiten los educadores con ese par de palabras. En cuanto al "usted" utilizado por P048, es una forma de tratamiento pronominal que establece mayor distancia social entre los interlocutores. Lo usamos cuando no conocemos a la otra persona u ocupa un rol social de más estatus que el nuestro, también cuando no queremos generar confianza con los demás. Para el ejemplo en cuestión, el "usted" 
remarca el efecto negativo de la ironía a través de explicitar la demostración de poder (Alba, 2002) por parte del profesor. En otras palabras, el educador, aparte de burlarse, exhibe e impone su estatus al estudiante. Es una de las ocasiones típicas en las que se configura la cultura del distanciamiento (Albelda y Briz, 2010). En síntesis, esta ironía es negativa, representa un ataque verbal, una demostración de poder, una burla y, si se quiere, podría ser una forma de reivindicar la asimetría social que tanto entorpece la relación profesor-estudiante en las aulas de clase.

A modo de conclusión de este apartado, tras la revisión y análisis de las muestras de ironías en las diferentes situaciones de aula, podemos concretar lo siguiente:

- En los cuatro contextos abordados los profesores usan la ironía, aunque es mayor el porcentaje que no lo hace.

- Los ejemplos analizados manifiestan, en mayor o menor grado, las tres funciones generales de la ironía que propone Alba (2002): ataque verbal, diversión y evaluación. Funciones que, por lo general, no operan por separado, sino que suelen darse en simultáneo y se complementan con funciones específicas: reproche, rapport building, queja, manifestación de poder, burla, etc.

- En los tres primeros contextos se observa que la diversión y el humor son inherentes a las ironías de los profesores. Estrategia que busca, ante todo, modificar el comportamiento de los estudiantes.

- En el último contexto no está claro si a través de las ironías se pretende cambiar el comportamiento de los estudiantes o si, más bien, lo que prevalece es la burla y la manifestación de poder.

- En cuanto a la forma de las ironías, no hay un patrón común, ya que unas están compuestas por enunciados que parecen ecos de la cotidianidad, otras se configuran con elementos de la retórica y, como vimos en la última situación de aula, hay unas en simbiosis con formas de tratamiento.

\section{Los efectos perlocutivos de la ironía del profesor}

Como de todos es sabido, el devenir histórico de los estudios lingüísticos ha superado varios paradigmas que fluctúan desde el componente de la lengua hasta el componente del habla, desde la estructura formal hasta el interés por el sentido, desde lo oral hasta lo escrito, desde el texto hasta el discurso, y cada paradigma va superando o construyéndose sobre el anterior. Con el surgimiento de la pragmática y su centro de estudio -el habla-, la cotidianidad lingüística exige nuevos enfoques para el análisis del texto hablado. Muchos fueron los teóricos y las metodologías empleadas al igual que la focalización del objeto de análisis. Wittgenstein (1953/1988) desde su formación matemática y su dogmatismo filosófico finalmente logra visualizar el lenguaje como un juego, no como un estamento estático, inerte, sino como una estructura cambiante, que se renueva con variadas intenciones y funciones de acuerdo con los intereses y contextos comunicativos; allí el ideolecto aunado al contexto 
comunicativo construye expresiones de variados y diversos matices que son objeto de estudio pragmático desde la mirada de Austin (1962/1971) y Searle (1969/1980), a partir de los actos de habla. Actos que fluctúan desde lo realizativo y lo constatativo hasta lo perlocutivo que, en palabras de Austin, es el acto que se realiza por el hecho de decir algo con una intención implícita y se refiere a los efectos producidos; justamente, a partir de este concepto gira el presente análisis en un contexto académico delimitado.

Los enunciados en sí tienen diferentes intenciones cuando interactuamos con el otro o los otros y esperamos modificar el comportamiento de nuestros enunciatarios; esta intención puede presentarse de forma positiva o negativa; estos efectos son más evidentes si el enunciador recurre a diferentes estrategias discursivas para lograr sus propósitos comunicativos, entre ellas, el uso de la ironía, el sarcasmo, la burla o el insulto. En cuanto a las ironías de efecto negativo, vale decir que se constituyen en una herramienta inadecuada a la hora de querer establecer puentes de comunicación con los estudiantes, pues, en lugar de que participen en las clases exponiendo sus pensamientos, se van a sentir inseguros y aterrados si contestan mal, por lo que pueden ser presa de las burlas e ironías por parte del profesor. Por otro lado, las de efecto positivo permiten que el estudiante explore sus pensamientos y llegue a las respuestas por medio de la reflexión y los comentarios que el profesor le formule. A continuación, revisaremos estos dos grupos de ironías desde los resultados conseguidos en la investigación:

\section{Ironías de efecto negativo}

Las diferentes formas de expresión, al igual que el efecto perlocutivo de los enunciados, vienen explicados por Torres-Hernández (2012), quien los enumera y contrasta en una escala clasificatoria que da cuenta de los efectos negativos de la ironía y cómo algunos de los aspectos de estos enunciados afectan de diferentes formas al alumnado, a saber:

- Burla o broma: la burla hace parte de los elementos de la ironía; va dirigida al estudiante como persona, más que a sus ideas. Esta se diferencia de la broma, en la medida en que la segunda busca, principalmente, despertar alegría; su intención es menos destructiva. Sin embargo, la burla conlleva una intencionalidad subyacente en la que su fin es "molestar" al otro. También, podemos diferenciarlas, ya que en la broma uno se ríe con el otro, mientras que en la burla uno se ríe del otro.

- Ridiculización: aparece cuando el profesor reduce a su estudiante, comparándolo con otras personas o situaciones que connoten cierto tipo de rechazo hacia lo que es planteado por el estudiante. De igual forma, se somete al estudiante a cierto tipo de humillación, pues lo que se busca al ridiculizarlo es poner en duda sus habilidades cognitivas y sus destrezas. La diferencia principal entre esta y la burla radica en que, en la ridiculización "el estudiante 
no está ostentando nada, solo es la víctima de su docente" (Torres-Hernández, 2012, p. 468).

- Reproche: se da cuando el profesor critica o reprueba las acciones del estudiante. Estas expresiones se dan en un tono negativo que busca "censurar" al estudiante más que corregirlo.

- Irrespeto: nace de las humillaciones y expresiones ofensivas que hieren e incomodan al estudiante y lo afectan de manera personal. Allí se transgrede el umbral de lo privado y aparece la ironía prototípica que busca afectar de manera personal, moral, sentimental y actitudinal.

Los actos disruptivos de los que hablábamos en el apartado de Las funciones de la ironía del profesor de bachillerato despiertan, para el caso de nuestra investigación, las más diversas ironías de efecto negativo. Ante ellas, muchos profesores entrevistados manifiestan haberse sentido ofendidos y humillados por expresiones de sus maestros en épocas pasadas. La Tabla 5 recoge algunas de las ironías referidas por los profesores al respecto:

Tabla 5. Algunas ironías de efecto negativo referidas por los profesores

\begin{tabular}{|l|l|}
\hline \multicolumn{1}{|c|}{$\begin{array}{c}\text { Código del } \\
\text { profesor }\end{array}$} & \multicolumn{1}{c|}{ Ejemplos } \\
\hline P022 & Vamos a hacer silencio que el compañero está que nos habla. \\
\hline P042 & Dígale a su mamá que cuando tenga hijitos no tome caldo de lora. \\
\hline P047 & ¿Cómo apagamos el radioloco? \\
\hline P083 & Descubrió el agua \\
\hline
\end{tabular}

Reconocemos que burlas, ridiculizaciones, reproches e irrespetos pueden desembocar en el fenómeno del insulto como expresión suma de la intolerancia. Al respecto, varios datos vienen al caso; un $65 \%$ de los profesores entrevistados reconocen haber tenido a algún profesor irónico que les marcó su vida; y de este grupo un $30 \%$ expresa la sensación de haberse sentido ofendidos. Ese porcentaje manifiesta, algo así como la presencia de heridas lingüísticas que marcaron su ser. Tales efectos desestabilizan el sistema didáctico que se gesta entre profesor, estudiantes y saber, lo que afecta el disfrute, el placer y la empatía como índices de una vida de aula saludable. Allí las discordias, en lugar de enseñar, distancian; ya no hay intenciones didácticas y pedagógicas que se concreten en transformaciones efectivas; prima el acoso y la intimidación, lo que da paso a efectos negativos de odio y rencor.

A todas luces, el panorama resulta bastante complejo de parcelar en conceptos precisos, ante la cercanía - no solo conceptual, sino perlocutiva - de fenómenos que aquí se comprometen, entre ellos, la ironía y el sarcasmo que parecen emparentarse en el aula en un continuum que va desde el silencio no asertivo hasta el insulto; si bien 
es cierto que sobre ironías y sarcasmos, ya Attardo et al. (2003) habían confesado: "there seems to be no way of differentiating reliably between the two phenomena" ( $\mathrm{p}$. 243), el hecho de que en teoría resulte difícil delimitar la ironía del sarcasmo nos impele a buscar la diferencia en la práctica, ante todo en las reacciones del receptor, pues lo que para un profesor pasa por una simple broma, en el mundo de ciertos estudiantes puede constituirse en un sarcasmo que raye en el insulto. Esta hipótesis de trabajo, según la cual las diferencias entre ironías, sarcasmos, ofensas, humillaciones o bromas... se juegan en el territorio del receptor, ya fue analizada en un avance de esta misma investigación (Caro, 2020). Sin embargo, para los propósitos del presente artículo, se retomará bajo la propuesta general del tacto y la prudencia, en tanto actitudes esenciales con las cuales el profesor debería enfrentar sus interacciones con el estudiante. Tales consideraciones forman parte de la discusión de resultados que se presenta más adelante.

\section{Ironías de efecto positivo}

En la muestra analizada, como ironías de efecto positivo sobresalen los regaños humorísticos e irónicos que los profesores suelen usar a la hora de "reprender" a sus estudiantes cuando estos llegan tarde a clase y que fueron analizados en la situación 1 del apartado de Las funciones de la ironía del profesor de bachillerato. Como allí lo indicábamos, los profesores hacen uso de la ironía con tintes de humor para "reprobar" una acción específica en sus estudiantes, lo que serviría para despojar a estos "regaños" de ciertas connotaciones groseras o hirientes y, en este caso, sea la risa y el humor lo que esté más presente. Esto podríamos denominarlo como los lugares comunes de la ironía, que son socialmente convertidos en dichos o frases comunes.

De otro lado, constatamos el hecho de que el enunciado irónico no se interpreta exclusivamente desde posibilidades antifrásticas - según la idea clásica de que expresa lo contrario de lo que se afirma (inversione verborum) - sino que se ponen en juego otros sentidos, como el de la burla fina y disimulada, la camaradería, la reconvención ingeniosa, etc. Con respecto al uso y al efecto perlocutivo de la ironía de efecto positivo, los profesores justifican su utilización de diversas maneras; la Tabla 6 recoge algunas de ellas: 
Tabla 6. Algunas razones para el uso de la ironía en el aula

\begin{tabular}{|l|l|}
\hline $\begin{array}{c}\text { Código del } \\
\text { profesor }\end{array}$ & \multicolumn{1}{c|}{ Ejemplos } \\
\hline P02 & $\begin{array}{l}\text { Como efecto positivo se hace la clase más amena; a veces las situaciones en } \\
\text { clase son muy tensas, entonces recurriendo a las ironías se baja un poquito la } \\
\text { tensión }\end{array}$ \\
\hline P04 & $\begin{array}{l}\text { Que los estudiantes se sientan un poquito más en confianza; para mí es más } \\
\text { positivo, que uno se atreva a romper esa barrera }\end{array}$ \\
\hline P030 & $\begin{array}{l}\text { Positivos, porque ellos se ríen y comprenden cuál es el mensaje que va detrás } \\
\text { de algo irónico }\end{array}$ \\
\hline P043 & $\begin{array}{l}\text { Una ironía podría ser constructiva a la hora de que puede ser algo que a todos } \\
\text { nos pareció gracioso, algo que ocurrió en el aula, o algo que uno dice al respecto } \\
\text { o algo que está pasando, y uno lo dice de una manera graciosa y pues todos se } \\
\text { ríen, entonces comienza a haber un efecto como que el estudiante tiene una } \\
\text { cercanía con el docente y la cercanía es muy importante }\end{array}$ \\
\hline
\end{tabular}

Aunque en el apartado siguiente ampliaremos este asunto, podemos adelantar desde aquí que, al ironizar, siempre hay una intención y un propósito; quien utiliza la ironía es consciente del efecto perlocutivo que va a causar en el otro y muchas veces logramos hacer sentir cómodos e incómodos a nuestros estudiantes en los espacios académicos. Así las cosas, los efectos perlocutivos son diferentes de acuerdo con la situación comunicativa, las intenciones y propósitos del enunciador, al igual que el contexto en el que ocurren. Puede primar la risa, el humor, el carnaval, al igual que los odios y los rencores y estas experiencias discursivas van a estar presentes en oyentes-receptores por mucho tiempo. Algunos profesores defienden la ironía en el aula a capa y espada por sus efectos positivos; otros ni siquiera la utilizan por temor a irrespetar al otro o simplemente para evitar inconvenientes legales. Personalidades de profesores abundan en los contextos educativos desde el más respetuoso hasta el más ordinario, desde el más osado hasta el más conservador, desde el más frágil hasta el más fuerte; todos con estrategias retóricas diferentes y estilos discursivos ya definidos. No hablamos por hablar, aunque muchas veces sucede que las saetas de las palabras ya fueron lanzadas; las disculpas pasan a segundo lugar y los odios y amores continúan su curso, aunque las cicatrices tarden en sanar y ello debido a que muchos actores no entienden las expresiones, las malinterpretan o simplemente evocan ese sinsabor negativo que se queda impregnado del recuerdo, dando entrada al desinterés, la apatía o a la deserción. Al contrario, las ironías con efecto positivo y humorístico permiten la acción, la exploración, el disfrute y la camaradería como ambientes propicios para las intervenciones didáctico-pedagógicas, espacios académicos amenos llenos de confianza y participación. En conclusión, muchos recordarán la ironía con un efecto positivo, otros con un efecto negativo, pero la ironía en el aula siempre será recordada. 
Conexos a estas consideraciones, emergen otros frentes de resultados que, por razones de extensión, no alcanzaríamos a desglosar suficientemente en este artículo, pero que, al menos, presentamos grosso modo, con el fin de avanzar sobre su base en la discusión que viene más adelante. Por ejemplo, identificamos en el corpus de las entrevistas niveles de asertividad (26\%), ironía antifrástica (38\%), sarcasmo (26\%) y ofensa (10\%). Resaltamos, además, que el $60 \%$ de los profesores entrevistados considera que, de sus ironías, puede resultar algún efecto positivo en sus estudiantes; por el mismo rango, un $63 \%$ reconoce la presencia de ciertos factores que los lleve a refrenar sus deseos de ironizar; y por último, un 75 \% reconoce en la ironía - así no la practique - cierto valor pedagógico o didáctico. Todos estos datos aportan insumos importantes a la discusión de resultados que presentaremos, a continuación, en torno al tacto y la prudencia, como actitudes esperadas del profesor ante la elección de ironizar o no en medio de las diversas interacciones de aula.

\section{DiscUSIÓN}

Como lo dejan ver los anteriores resultados, el panorama de la ironía del profesor de bachillerato en la población investigada se muestra por completo variopinto. Su discurso oral se mueve por un espectro amplio de formas comunicativas que van desde la renuncia consciente y declarada de la ironía hasta territorios en los que esta se desdibuja y toma la forma de ofensa, tal como lo describe esta investigación en uno de sus avances anteriores: "la ironía introduce distintos niveles de tensión de aula, a través de sus tipologías más comunes: antífrasis, mención ecoica inmediata, asteísmo, hipocorismo, sarcasmo y sátira, entre otros" (Caro, 2020, p. 380). Ante esta situación, bien podría el lector preguntarse, de modo un tanto hamletiano, por ironizar o no ironizar en el aula. Al respecto, no podríamos ofrecer una opción salomónica, pues, tal como lo afirman diferentes profesores entrevistados, los peligros de que una ironía se malinterprete son altos; las entrevistas recogen las más diversas anécdotas de colegas en problemas legales o incluso en amenazas de muerte, por culpa de una ironía que se salió de cauce. En este sentido, son inobjetables las observaciones de uno de ellos: "muchas veces se hieren susceptibilidades, porque a la persona a la que uno le dice la ironía no la entiende, la toma literal y se genera una discusión, una controversia, incluso un problema" (P010).

Sin embargo, tampoco podríamos caer en el extremo de satanizar la ironía. Justamente, el título del trabajo de Huang et al. (2015) pondera al sarcasmo como "the highest form of intelligence" (p. 162). Un corolario a tales ponderaciones lo podrían aportar las respuestas de P015 a la pregunta por el posible valor pedagógico o didáctico de la ironía: «casi cualquier escenario del ser humano permite o habilita la ironía, formal o informal. Si lo hablamos desde la academia, sí que se utiliza como estrategia de interacción y más allá de esto, si no estoy equivocado, hay mucha relación con el sarcasmo, con el humor negro, y para mí eso siempre es exquisito, cualquier escenario de la vida se habilita para ello». De esa misma orilla argumentativa, emergen otras concepciones afines de la ironía como: 1. contradicción 
consentida (Mizzau, 1984) que se podría corroborar desde las declaraciones de P031: «En los momentos en que el profesor usaba la ironía o el sarcasmo, fue para hacernos caer en cuenta que nos faltaba disciplina, compromiso, proyectarnos más hacia lo que estábamos estudiando»; 2. estrategia de cortesía (Alvarado, 2009) que dialoga con las afirmaciones de P043: «cuando hay empatía con la persona uno podría decir: 'bueno, vamos a copiar la tarea o vamos a copiar del cuaderno del compañero que fue el más malo de todos'»; 3. habilidad metarrepresentacional (Ruiz, 2008) que se ilustra en las aseveraciones de P015: «a mí me gusta la observación; entonces si el estudiante llega tarde, yo lo observo, si no está bien vestido, o si no se amarró los zapatos, o si es muy alto, yo digo: 'bueno, ¿agachándote te demoraste media hora o qué?'; cosas de ese estilo, trato de no ser ofensivo sino de generar como un ambiente de empatía». Todo este potencial polifónico de consideraciones nos lleva a aseverar, con TorresHernández (2012), que la ironía se erige como "una nueva forma comunicativa en las aulas de clase y la más pertinente para la época" (p. 471).

No obstante, la introducción de la ironía en el aula le exige al profesor tacto y prudencia:

Tacto y prudencia se convierten en la vía actitudinal a través de la cual accedemos al principio del aptum, aquel al que define el segundo miembro del título de la obra de Cattani (2010), Expresarse con acierto (2010): una palabra para cada ocasión, una ocasión para cada palabra. Para nuestros intereses investigativos, el profesor, dotado de tacto y prudencia, lee la ocasión (entendida en la concepción englobadora de las situaciones de locutor e interlocutor, tiempo y espacio) y define la palabra adecuada (asertiva, antifrástica o sarcástica). Ejercicio, de regreso al título de Cattani, no solo propio del expresarse, sino también del obrar, del enseñar y del vivir... con acierto. (Caro, 2020, p. 382).

El tacto y la prudencia, emparentados con la conciencia por los efectos perlocutivos de la ironía (vid supra), marcan una importante tendencia en las consideraciones de los profesores entrevistados para evitar problemas al ironizar. La opinión de uno de ellos resulta representativa: "Cuando de pronto uno tiene un estudiante muy cansón, muy maluquito, al que a veces uno le quiere decir cosas, pero del que uno sabe que es un estudiante problemático, entonces más bien tiene que ir uno con mucho tacto para evitar lo que estamos hablando ahorita, que de pronto con la ironía se puede llegar a ofender a una persona" (P016). Sentada esta postura como premisa para la población entrevistada, esbozamos sucintamente tres estrategias que surgen del diálogo con los mismos profesores como maneras de concretar la actitud de tacto y prudencia en los intercambios comunicativos signados por la ironía. Se trata de la conciencia de la polisemia en los juegos irónicos; la empatía y la confianza como condiciones sine qua non para la ironía; y el ataque hacia las circunstancias, pero nunca hacia las esencias. 


\section{La conciencia de la polisemia en los juegos irónicos}

Sabemos muy bien que los textos irónicos son inestables, dúctiles, lábiles, en virtud de su polifonía, su función ecoica, su caudal argumentativo, su retórica, su poética y la inversión de las máximas neogriceanas (Alvarado, 2009; Rodríguez, 2009; Ruiz, 2012; entre otros). Más aún, el estado del arte revela que sus niveles de comprensión en diversos grados educativos y alrededor de distintos géneros tiende a ser baja (Arrieta, 2013; Castrillón y Caro, 2011; Crespo et al., 2007; etc.).

Para el caso de la investigación que nos ocupa, salta a la vista el problema de la polisemia como espada de Damocles que pende sobre el profesor a la hora de lanzar una ironía. Entre las diversas anécdotas que introducen las entrevistas, introducimos, por sus efectos, la que refiere P099. Cierto estudiante llega tarde al aula y, lejos de sentirse intimidado por ello, interrumpe constantemente la clase con apuntes inoportunos y charlas en voz alta. El profesor, molesto por tales disrupciones, se acoge a la tradición oral propia de la región y le espeta la sentencia "¡tras de ladrón, bufón!" 7 , cuyo sentido figurado reprocha el hecho de que alguien, aparte de una falta previa, introduzca sin vergüenza una nueva transgresión. El estudiante reacciona airadamente, porque interpreta literalmente la expresión como una denuncia de su condición de reconocido ladrón de la zona. El hecho escala a tal grado en su gravedad, que esa tarde el profesor debe salir del plantel custodiado por la policía ante las inminentes amenazas de muerte. Este ejemplo se constituye en palmaria evidencia de lo frágil que puede resultar la comprensión de la ironía desde la polisemia de los términos en los que se fragüe. Nada garantiza que el interlocutor tome el camino de lo literal ante una alusión figurada; nada asegura que el hablante elija el sentido menos indicado de la baraja polisémica de una palabra. Estas observaciones le dan la razón al $40 \%$ de los entrevistados que, temerosos y reticentes frente al tema, advierten efectos negativos en las ironías que pueden llegar a los estudiantes, en virtud de que no siempre la intención de un ironista encuentra su correlato en la reacción del ironizado; de ahí que prefieran, en la mayoría de los casos, no ironizar. Por ello, el profesor irónico revestido de tacto y prudencia, antes de ironizar, debe sopesar el mayor número de posibles sentidos de las palabras que utilizará para prever los efectos perlocutivos de su ironía. En este orden de ideas, el precio que debe pagar el profesor por la promiscuidad de las asociaciones que haga el estudiante, al contacto con un enunciado irónico, puede ser bastante alto. En virtud del juego con la ambigüedad -o con la violación al principio levinsoniano de informatividad, según Rodríguez (2009) y Ruiz (2012) - se hace un poco más difícil para el hablante descartar las asociaciones promiscuas; más bien, un enunciado irónico vive de dicha promiscuidad. Tener en cuenta esta condición pudiera evitar que los juegos del

\footnotetext{
${ }^{7}$ Aunque esta expresión, stricto sensu, no podría considerarse como ironía, la incluimos en el análisis, porque así la ha considerado el entrevistado P099 y desde allí fundamenta sus posiciones al respecto. La recurrencia detectada en el corpus de este tipo de imprecisiones podría dar paso a la construcción de una nueva investigación en torno a los imaginarios de lo que es ironía para los docentes y sus confusiones con los territorios del insulto, el disfemismo o el simple sentido del humor.
} 
profesor irónico colisionen con el mundo de sus estudiantes por culpa de las promiscuidades de las palabras, de su condición polisémica, de su ADN eminentemente polifónico.

Todo esto abre el camino a nuevas investigaciones que se acerquen a ese cúmulo complejo de condiciones que rodean la recepción de la ironía en el mundo del estudiante. El haber adelantado esta investigación nos deja la lección de que para indagar por los efectos perlocutivos de la ironía no es suficiente con escuchar las voces de los profesores que la lanzan, sino que se hace necesario auscultar las percepciones de los estudiantes que la reciben; esfuerzo que, sin duda, exige de un proyecto aparte centrado en rastrear el pathos que deja la ironía en estos jóvenes. Ya en una investigación anterior, Caro (2017) había rastreado los comentarios de los lectores en la Red a un texto argumentativo irónico y había llegado a la conclusión de que "los finos aleteos sociodiscursivos" de una ironía, "al estilo de un efecto mariposa, desencadenan una tormenta patética al otro lado del texto" (p. 114). Seguramente estas nuevas investigaciones se ocupen de preguntas como: ¿qué redes asociativas construye e integra el estudiante al escuchar una ironía de su profesor?, ¿cuál es el nivel de conocimientos previos necesarios para comprender una ironía?, ¿qué papel juegan las emociones del estudiante en la recepción de una ironía? y ¿cuánta guía es óptima para el aprendizaje de la comprensión de la ironía?, entre tantas otras.

\section{La empatía y la confianza como condiciones sine qua non para la ironía}

Un aporte representativo de la investigación sobre las interacciones signadas por la ironía verbal tiene que ver con su desarrollo adecuado en medio de ambientes caracterizados por la confianza y la empatía. Revisaremos aquí tres trabajos.

El primero de ellos viene de Pexman y Zvaigzne (2004). Allí las investigadoras, a partir de la premisa de que el terreno común entre el hablante y el destinatario es importante para la comprensión de la ironía verbal, analizan los efectos de uno en particular: el de las relaciones solidarias, caracterizadas por la cercanía, la empatía y el apoyo mutuo. Defienden las autoras el crucial papel que juegan en estos procesos los factores sociales; de ahí que concluyan: "We argue that a solidary relationship between speaker and addressee facilitates the metarepresentational inferences needed to understand irony" (p. 143).

El segundo, correspondiente al trabajo de Nicholson et al. (2013), asevera:

Results in this paradigm showed that children's irony appreciation and processing were correlated with their empathy development, suggesting that empathy or emotional perspective taking may be important for development of irony comprehension. Further, children's processing of irony was consistent with an interactive framework, in which children consider ironic meanings in the earliest moments, as speech unfolds. These results provide important new insights about development of this complex aspect of emotion recognition. (p. $1)$. 
Tales hallazgos no distan mucho de las conclusiones que Huang et al. (2015) señalan en torno a la importancia de ambientes llenos de confianza para el intercambio irónico: “The positive effect of expressing or receiving sarcastic (vs. sincere or neutral) remarks on perceptions of conflict will be reduced when individuals express the remarks to or receive the remarks from someone they trust" (p. 165). Marcamos en cursivas esta conclusión, pues a ella parecen confluir las entrevistas realizadas. Para la muestra, una profesora de matemáticas (P076) confesó que tenía, por sarcasmo de cabecera, responderles a los estudiantes que le pedían opciones de recuperar su asignatura, la expresión «¿Qué le voy a dar oportunidades si usted ya huele a formol?». Ese sarcasmo - que es eco de la expresión con la cual la sociedad, en las épocas de la violencia más cruda de la historia reciente colombiana, signaba a quienes por su valentía corrían peligro de muerte - cobraba, según la profesora, efectos de adhesión entre los estudiantes y, lejos de cortar lazos, los estrechaba aún más, pues ella sabía muy bien a quién le podía lanzar la sentencia de marras: a jóvenes extrovertidos, de estilo de aprendizaje activo, que entendían la broma pesada de su profesora y que veían en la insincera amenaza, la clara posibilidad de ganar la materia si se esforzaban un poco más. A esto se refiere buena parte del $63 \%$ de los entrevistados cuando reconoce la presencia de factores que los lleva a refrenar sus deseos de ironizar; no en vano P02 indica que «el valor de la ironía es más bien didáctico, pues hace la clase un poquito más amena, para que los estudiantes se sientan en un espacio familiar y lleno de confianza, sin llegar al caso de vulnerar su 359 personalidad».

Así las cosas, la configuración de ambientes de confianza y empatía se erige como respaldo para que la ironía crezca sin traumatismos en el aula y alcance - más allá de la de lubricante social (Huang et al., 2015) - la condición de lubricante didáctico para mover ambientes de aprendizaje más dialógicos, dinámicos y creativos.

Naturalmente la comprensión y construcción de tales ambientes de aprendizaje exigen la puesta en marcha de investigaciones no solo de corte históricohermenéutico, sino también crítico-social (desde diseños de investigación-acción) que en ambientes situados de práctica le tomen el pulso a los intercambios irónicos entre profesor y estudiantes para responder preguntas como: ¿hasta qué límites se ponen en juego la confianza y la empatía para sobrellevar una ironía?, ¿qué otros factores favorecen u obstaculizan la recepción de la ironía por parte del estudiante? y ¿cuál es el papel de los contextos situacionales, lingüísticos y socioculturales en la recepción de la ironía en el aula?

\section{El ataque hacia las circunstancias, pero nunca hacia las esencias}

Una curiosa tendencia que aportan los resultados analizados en el apartado de Las funciones de la ironía del profesor de bachillerato se convierte en pertinente lección pedagógico-didáctica para el uso de la ironía en el aula. Más allá de los estrechos márgenes que se presentan entre el ironizar o no de los tres primeros casos, llama la atención la contundente negativa a hacer ironías en torno a una respuesta equivocada 
de los estudiantes. Un resultado de esta naturaleza deja ver cierta licencia por el manejo de la ironía en situaciones en las que primen factores circunstanciales (como las llegadas tarde o el incumplimiento con la entrega de tareas), pero también un prudente rechazo por usarla cuando se comprometen algunos rasgos individuales o se pone en peligro algo de la esencia individual de los estudiantes. Salvo algunos ejemplos documentados en el apartado de Los efectos perlocutivos de la ironía del profesor y que se incluyen en el $22,11 \%$ de quienes ironizan al respecto, el dato de un $77,88 \%$ de entrevistados que se abstienen de hacerlo se corrobora con declaraciones del siguiente tenor que se recogen en la Tabla 7:

Tabla 7. Algunas razones para evitar la ironía sobre respuestas incorrectas de los estudiantes

\begin{tabular}{|l|l|}
\hline $\begin{array}{c}\text { Código del } \\
\text { profesor }\end{array}$ & \multicolumn{1}{c|}{ Ejemplos } \\
\hline P035 & $\begin{array}{l}\text { [1] Para nada. Me parece que si un estudiante responde o quiso participar para } \\
\text { mí eso ya es una ganancia. Si era algo obvio, simplemente lo corrijo y ya }\end{array}$ \\
\hline P038 & $\begin{array}{l}\text { [2] No, cuando eso pasa, le digo al estudiante "piénsalo bien", “¿consideras que } \\
\text { verdaderamente esa es la respuesta?", pero ahí no utilizo la ironía }\end{array}$ \\
\hline P050 & [3] No, porque siento que sería una burla \\
\hline
\end{tabular}

Aquí los temores a desestimular la participación y la autoconfianza [1], la preferencia por la asertividad [2] y el miedo a caer en la burla hacia el otro [3] son indicios claros de una conciencia sobre los posibles efectos negativos de la ironía cuando se cuestiona la capacidad intelectual del estudiante, su solvencia teórica y, en última instancia, su autoimagen ante el grupo. Esto nos recuerda el trabajo de Padilla y Alvarado (2010), "Being polite through irony", en el que los investigadores hacen un recorrido por diversos ejemplos en los que se manifiesta claramente la presencia de ironías prototípicas de corte negativo (pp. 60-63) y positivo (pp. 64-67). Impulsados por los alcances pragmáticos de la muestra estudiada, resaltan los autores la influencia de dos factores que determinan el carácter positivo o negativo de las ironías en la conversación: 1. La relación previa entre los interlocutores; y 2. Su reacción o actitud hacia el enunciado irónico en el mismo momento en que fue producido (p. 67). El primer factor, que tiene que ver con las relaciones de empatía y confianza entre interlocutores para impulsar el efecto positivo de la ironía, fue estudiado en la clave anterior; mientras que el segundo revela su importancia en el asunto que aquí analizamos, pues las reacciones irónicas de un profesor ante la respuesta equivocada de un estudiante refuerzan la carga negativa del intercambio comunicativo. Ya sabemos, por lo dicho en el apartado de Las funciones de la ironía del profesor de bachillerato, que una ironía desde la investigación de Alba (2002) - comporta una triple función de ataque verbal, evaluación y diversión; esto en el plano psicológico de un estudiante que intenta participar de la clase bien podría representar un triple efecto adverso, pues no solo 
arrastra la evaluación negativa de su respuesta, sino también el ataque verbal y el pasar por objeto de diversión ante la clase; esto último lo analizamos en el apartado de Los efectos perlocutivos de la ironía del profesor como efecto devastador de una ironía inadecuada para el tipo de estudiante y el contexto comunicativo específico. Ello podría resumirse en una máxima del tipo evita la ironía para lo que pueda representar una amenaza a la autoestima; o mejor aún; duro con las circunstancias, pero suave con las esencias.

Este terreno, resbaladizo per se, debe atraer nuevas investigaciones de corte diverso que se ocupen de esos factores más impredecibles que rompen el delgado hilo que separa a la ironía de la ofensa, e.g.: los estilos de aprendizaje, las historias personales, los rasgos específicos de las comunidades discursivas, las memorias culturales de la palabra y el trasfondo altamente semiotizado de lo no verbal. Tales investigaciones aportarían no solo a la comprensión de un fenómeno tan polifónico como la ironía y su diferencia con conceptos cercanos (tal como lo explicábamos en el apartado Los efectos perlocutivos de la ironía del profesor), sino también a la promoción de un profesor dotado de conciencia del lenguaje que alcance a discernir el anhelado kayrós del acto comunicativo; la conciencia de saber cuándo debe mostrarse asertivo, cuándo enfrentar las tensiones con asertividad, cuándo juguetear con una ironía, cuándo espetar un sarcasmo, cuándo remover con una sátira... o, incluso, cuándo guardar prudente silencio.

\section{CONCLUSIONES}

Analizar la ironía del profesor de bachillerato en el contexto específico de colegios oficiales arroja un panorama diverso de observaciones que, para el caso de este artículo, se recoge en dos frentes concretos. El primero identifica en la ironía del profesor claras funciones de ataque verbal, evaluación y diversión, a la luz de los estudios de Alba (2002); a propósito, destacamos que las ironías en las situaciones de aula abordadas acogen un conjunto de funciones latentes, que suelen manifestarse al unísono o, si se prefiere, en un mismo pálpito. El segundo aborda los efectos perlocutivos que puede suscitar la ironía en el estudiante, desde las consideraciones de Torres-Hernández (2012); allí podemos constatar que tanto el estilo como la retórica en el aula de clase adquieren diferentes matices e intenciones dentro de la situación de enunciación. Tales hallazgos determinan tres claves pedagógico-didácticas que se pueden desprender de la actitud de tacto y prudencia que debe caracterizar al profesor irónico en el aula, y que pueden expresarse en términos de la conciencia de la polisemia en los juegos irónicos; la empatía y la confianza como condiciones sine qua non para la ironía; y el ataque hacia las circunstancias, pero nunca hacia las esencias. En cuanto a la primera, el profesor debe ser consciente de que la ironía - al contrario del hablar directo y asertivo - elige el camino de la ambigüedad de los sentidos y de las intenciones encubiertas, lo que puede deparar en comprensiones equívocas por parte del estudiante que malogran las pretensiones iniciales y disparan los efectos hasta alcances indeseados. En cuanto a la segunda, el profesor está llamado a construir 
primero canales de confianza y empatía con sus estudiantes, a través de los cuales pueda fluir el caudal tantas veces turbulento de la ironía, sin que se desborde hacia los territorios de la ofensa, la humillación y el irrespeto. En cuanto a la tercera, el profesor debe recordar que la ironía - en virtud de las funciones tan diversas que comporta - puede irrumpir en el mundo del estudiante de modo impredecible y, en lugar de camuflarse por circunstancias que la atenúen, atacar el centro de las esencias y lastimar los esquemas personales más íntimos. Así pues, se trata de un maestro cultor del principio del aptum y del kayrós que sabe tirar del lazo de la ironía y elige el procedimiento preciso para lograr la tensión adecuada y la respuesta perlocutiva deseada en sus estudiantes.

Ahora bien, estas propuestas de resultados que aprovechan las claridades del estado del arte en cuanto al logos de la ironía, lejos de cerrar la discusión, abren el panorama a nuevas investigaciones que profundicen no solo en perfiles particulares del ethos irónico del profesor, sino también en sus condiciones de recepción, según el pathos del estudiante. Hay en esto último un particular desafío, pues sabemos del poderoso arsenal retórico y carnavalizante de la ironía, y hasta intuimos su potencial pedagógico-didáctico; pero aún tenemos muchas piezas de rompecabezas por juntar en cuanto a lo que puede significar la ironía en los universos únicos e irrepetibles de los estudiantes que la reciben.

\section{REFERENCIAS}

Alba, L. (2002). Análisis de las funciones y estrategias del discurso irónico [Tesis de doctorado]. Universidad Complutense de Madrid, Madrid, España. https:/eprints.ucm.es/id/eprint/3383/.

Albelda, M., y Briz, A. (2010). Aspectos pragmáticos. Cortesía y atenuantes verbales en las dos orillas a través de muestras orales. En M. Izquierdo y J. Enguita (Coords.), La lengua española en América: Normas y usos actuales (pp. 237-260). Universitat de Valencia.

Alonso, M. (1993). Ironía y comunicación: Quién es el irónico, quién la víctima y cuál la situación. Cognitiva, 5(1), 113-125. https://bit.ly/3vm1o3F.

Alvarado, B. (2009). Ironía y cortesía. En L. Ruiz y X. Padilla (Eds.), Dime cómo ironizas $y$ te diré quién eres (pp. 333-345). Peter Lang.

Arrieta, M. (2013). La ironía como recurso y estilo argumentativo: Una evaluación diagnóstica de la comprensión textual. En Lectura y escritura: Debates y desafíos para el mejoramiento de la calidad educativa (pp. 624-644). VI Congreso Nacional de la Cátedra Unesco.

Attardo, S. (2000). Irony as relevant inappropriateness. Journal of Pragmatics, 32(6), 793826. https://doi.org/10.1016/S0378-2166(99)00070-3.

Attardo, S., Eisterhold, J., Hay, J., y Poggi, I. (2003). Multimodal markers of irony and sarcasm. Humor: International Journal of Humor Research, 16(2), 243-260. https://doi.org/10.1515/humr.2003.012. 
Austin, J. (1971). Cómo hacer cosas con palabras (Trads. G. Carrió y E. Rabossi). Paidós. (Obra original publicada en 1962).

Bajtín, M. (1976). Carnaval y Literatura. Revista Eco, (134), 311-338.

Beristáin, H. (1995). Diccionario de Retórica y Poética (7ª ed.). Porrúa.

Caro, M. (2017). De la mariposa a la tormenta: Análisis de los comentarios de los lectores en la red a textos argumentativos irónicos. ELUA, 31, 97-116. https://doi.org/10.14198/ELUA2017.31.05.

Caro, M. (2020). El discurso oral del profesor de secundaria: Entre asertividad, ironía y agresión. En E. Serna (Ed.), Revolución en la formación y la capacitación para el siglo XXI (3ae ed., Vol. 2) (pp. 376-383). Instituto Antioqueño de Investigación.

Caro, M., Camargo, Z., y Uribe, G. (2020). Hacia una didáctica de la ironía desde la comprensión de columnas de opinión irónicas. En L. del Basto, Z. Camargo y C. Orozco (Comps.), La investigación en el Doctorado en Ciencias de la Educación RUDECOLOMBIA (Tomo 3) (pp. 32-94). Universidad Tecnológica de Pereira.

Castrillón, C., y Caro, M. (2011). La comprensión de lectura en los estudiantes de grado 9o del Municipio de Armenia: Análisis de resultados de un simulacro de pruebas SABER (2009). Cuadernos Interdisciplinarios Pedagógicos, 11, 11-20.

Crespo, N., Benítez, R., y Cáceres, P. (2007). La comprensión de las ironías orales. Estudios Filológicos, (42), 79-94. https://doi.org/10.4067/S0071-17132007000100005.

Ducrot, O. (1988). Polifonía y argumentación: Conferencias del seminario Teoría de la Argumentación y Análisis del Discurso. Universidad del Valle.

363 Gómez-Jordana, S. (2007). Empleo irónico del proverbio. Thélème. Revista Complutense de Estudios Franceses, 109-124. https://revistas.ucm.es/index.php/THEL/article/view/THEL0707110109A.

Gurdián-Fernández, A. (2007). El paradigma cualitativo en la investigación socio-educativa. CECC y AECI.

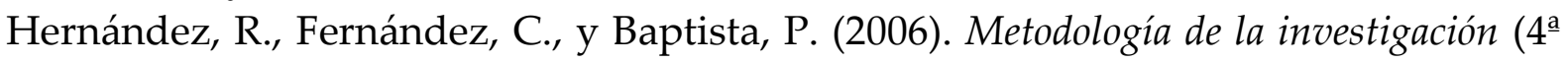
ed.). McGraw-Hill.

Huang, L., Gino, F., y Galinsky, A. (2015). The highest form of intelligence: Sarcasm increases creativity for both expressers and recipients. Organizational Behavior and Human Decision Processes, 131, 162-177. https://doi.org/10.1016/j.obhdp.2015.07.001.

Jankélévitch, V. (2012). La ironía. Me cayó el veinte.

Kalbermatten, M. (2006). Verbal Irony as a Prototype Category in Spanish: A Discoursive Analysis [Tesis de doctorado]. University of Minnesota, Minnesota, Estado Unidos. ProQuest Dissertations Publishing.

Martínez, M. (2004). Ciencia y arte en la metodología cualitativa. Trillas.

Mizzau, M. (1984). L'ironia: La contraddizione consentita. Feltrinelli.

Nicholson, A., Whalen, J., y Pexman, P. (2013). Children's processing of emotion in ironic language. Frontiers in Psychology, 4. https://doi.org/10.3389/fpsyg.2013.00691. 
Padilla, X., y Alvarado, B. (2010). Being polite through irony. En D. Koike y L. Rodríguez-Alfano (Eds.), Dialogue in Spanish: Studies in Functions and Contexts (pp. 55-68). John Benjamins. https://doi.org/10.1075/ds.7.04pad.

Pexman, P., y Zvaigzne, M. (2004). Does irony go better with friends? Metaphor and symbol, 19(2), 143-163. https://doi.org/10.1207/s15327868ms1902_3.

Placencia, M., Fuentes, C., y Palma-Fahey, M. (2015). Nominal address and rapport management in informal interactions among university students in Quito (Ecuador), Santiago (Chile) and Seville (Spain). Multilingua, 34(4), 547-575. https://doi.org/10.1515/multi-2014-0107.

Rodríguez, S. (2009). Una propuesta neogriceana. En L. Ruiz y X. Padilla (Eds.), Dime cómo ironizas y te diré quién eres (pp. 109-132). Peter Lang.

Ruiz, L. (2008). Las metarrepresentaciones en el español hablado. Spanish in Context, 5(1), 40-63. https://doi.org/10.1075/sic.5.1.04ruiz.

Ruiz, L. (2012). La lingüística del humor en español. Arco/Libros.

Searle, J. (1980). Actos de habla (Trad. L. Valdés). Cátedra. (Obra original publicada en 1969).

Sopeña, E. (1997). El concepto de Ironía: De tropo a ambigüedad argumentativa. Thélème. Revista Complutense de Estudios Franceses, (12), 451-460. https://revistas.ucm.es/index.php/THEL/article/view/THEL9797220451A.

Sperber, D., y Wilson, D. (1981). Irony and the use-mention distinction. En P. Cole (Ed.), Radical Pragmatics (pp. 295-318). Academic Press.

Torres-Hernández, F. (2012). El lugar de la ironía en el aula universitaria. Educación y Educadores, 15(3), 461-475. https://doi.org/10.5294/edu.2012.15.3.7.

Wittgenstein, L. (2017). Investigaciones filosóficas (Trad. C.U. Moulines). Instituto de Investigaciones Filosóficas y Secretaría de Cultura. (Obra original publicada en 1953).

Yus-Ramos, F. (2009). Saturación contextual en la comprensión de la ironía. En L. Ruiz Gurillo y X. Padilla (Eds.), Dime cómo ironizas y te diré quién eres (pp. 309-331). Peter Lang. 